\title{
A new look on reserves prediction of unconventional shale gas plays: moving from static parameters to dynamic, operation-based reserves' calculation
}

\author{
Fatimah Larasati Putri Pratami ${ }^{1} \cdot$ Steven Chandra ${ }^{1} \cdot$ William Angtony $^{1}$
}

Received: 24 October 2018 / Accepted: 7 February 2019 / Published online: 1 March 2019

(c) The Author(s) 2019

\begin{abstract}
As conventional oil and gas are now in a scarcer condition than they have ever been, attentions have shifted into unconventional resources. These unconventional resources, although abundant in nature, cannot be produced by conventional means economically. Therefore, efforts must be done to calculate reserves in such a fashion that uncertainties can be acknowledged, reducing errors and inaccuracies in the process. Researchers in the past have argued that uncertainties in reserve estimation cannot be measured by a single number and as the scale of reserve grows bigger, so will the uncertainties be. Two novel methods are developed from the basis of operation-based reserves' calculation, where development strategies namely hydraulic fracturing plans will be a deciding factor in determining reserves. These two methods are adapted from Monte Carlo-based approach, in which the first method will be using random numbers that are generated for listed properties to calculate ranged probability of reserves. The second approach is based on simple well-testing procedures that can also be referred to fracture design. The procedures are then compared to define practicality and situational capability of each method prepared. The models presented are dynamically flexible, due to the fact that they are integrated into development scenarios of the reserves.
\end{abstract}

Keywords Reserves estimation $\cdot$ Hydraulic fracturing $\cdot$ Reservoir development

\section{Introduction}

US Shale Gas Boom 2010 has sparked a previously unimaginable interest for energy-related companies worldwide. As the United States, who previously relied on the Middle East to provide for its fossil fuel demand, shifted its policy into self-dependency, countries worldwide are now in extensive search of previously omitted unconventional gas resources. As witnessed in hydrocarbon resources triangle seen in Fig. 1, unconventional oil/gas are located at the bottom of the food chain, implying relatively higher expertise is required to exploit the resources economically; however, it is incentivized with abundant mass available around the world.

The problem with economical exploitation of unconventional gas reserves lies in the reservoir rock properties itself. It is not often that unconventional gas/oil is located in lowpermeability, low-porosity reservoirs, rendering it unable to

Steven Chandra

steven@tm.itb.ac.id

1 Institut Teknologi Bandung, Bandung, West Jawa, Indonesia flow under conventional exploitation measures. However, the presence of natural fractures inside reservoir provides an important trait to be exploited. With the right treatments, namely hydraulic fracturing, economic exploitation of shale gas reserves is achievable.

Reserve evaluation of shale gas reserves is one of the most important aspects to be determined before any engineering plan or action should take effect. It is imperative to understand that shale gas reserve evaluation should be done in such manner that uncertainties can be acknowledged beforehand, rendering economic evaluation that is acceptable by operating companies. McGlade et al. (2013) provided an excellent review on currently accepted practices in shale gas reserve evaluation, namely (a) literature review/ adaptation of existing literature, (b) bottom-up analysis of geological parameters, and (c) extrapolation of production experience. Method (a) was proposed by Medlock et al. (2011) in which the specification of literatures taken into consideration ought to be from highly credible peer-reviewed scientific articles with experienced authors. The problem with this analogous method is that the properties are sometimes locally defined, rendering some models to be less accurate when applied

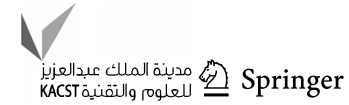




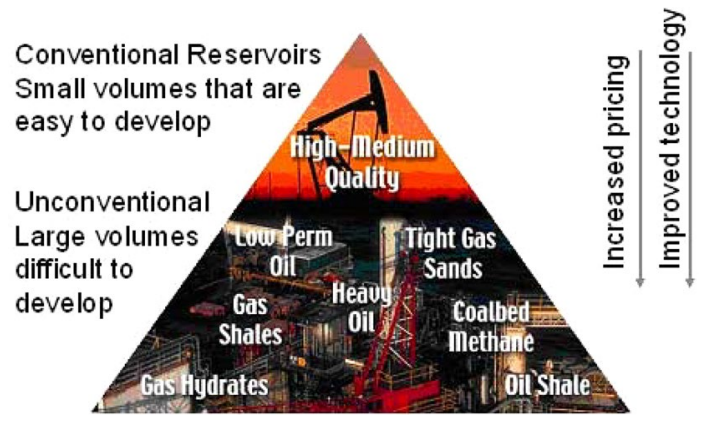

Fig. 1 Hydrocarbon resources triangle (Adapted from Martin et al. 2010)

to less similar reservoir. This method also presents its own problem when insufficient data apply due to regulation in some countries, therefore the uncertainty to this method is relatively high. Method (b) is the one that is frequently used by engineers worldwide to estimate shale gas reserves. The problem with this method is that geometrical calculation of shale gas reserves is not always accurate namely in rock properties distribution mechanism, which will be described later. Method (c) can only be used if and only if the reserve has been produced at a certain timeframe, and it is an imperative that constant model updating is done periodically after a particular sum of data is available. McGlade et al. (2013) also presented a tabulation on reserve evaluation in Marcellus Shale where several methods from numerous authors are presented with range of uncertainties as seen on Fig. 2.
From Fig. 2, it can be inferred that the situational attributes where every method mentioned has its own uncertainties as a function of numbers of drilled well. This creates a dilemma whether the reliability of the model in the long run and for universal utilization can be guaranteed.

On the basis of reserve estimation and uncertainties that follow, Ovreberg et al. (1992) were the first authors to introduce the concept of "error bar" which translates to uncertainties in calculation of hydrocarbon reserves. They argued that the deterministic concept cannot be verified statistically as errors in measurement, value-averaging, etc, will present during the calculation. Elliott (1995) proposes the application of uncertainties calculation combined with statistical approach to quantify inaccuracies and stochastic behavior of reserve calculation. Hefner and Thompson (1996) further emphasized on the application of stochastic approach, namely the P90, P50, and P10 terms to introduce uncertainties in reserve calculation as a tool to indicate investment feasibility. Demirmen (2005) argued that the previously available approaches of reserve estimation shall not be valid due to the fact that reserve can only be measured with $100 \%$ certainty if the last drop of oil has been extracted from the reservoir. Therefore, this publication addressed the issue of reserve uncertainty by combining reserve calculation with plan of development insights in unconventional gas recovery.
Fig. 2 Uncertainties in reserve assessment of shale gas reservoir (Adapted from McGlade et al. 2013)

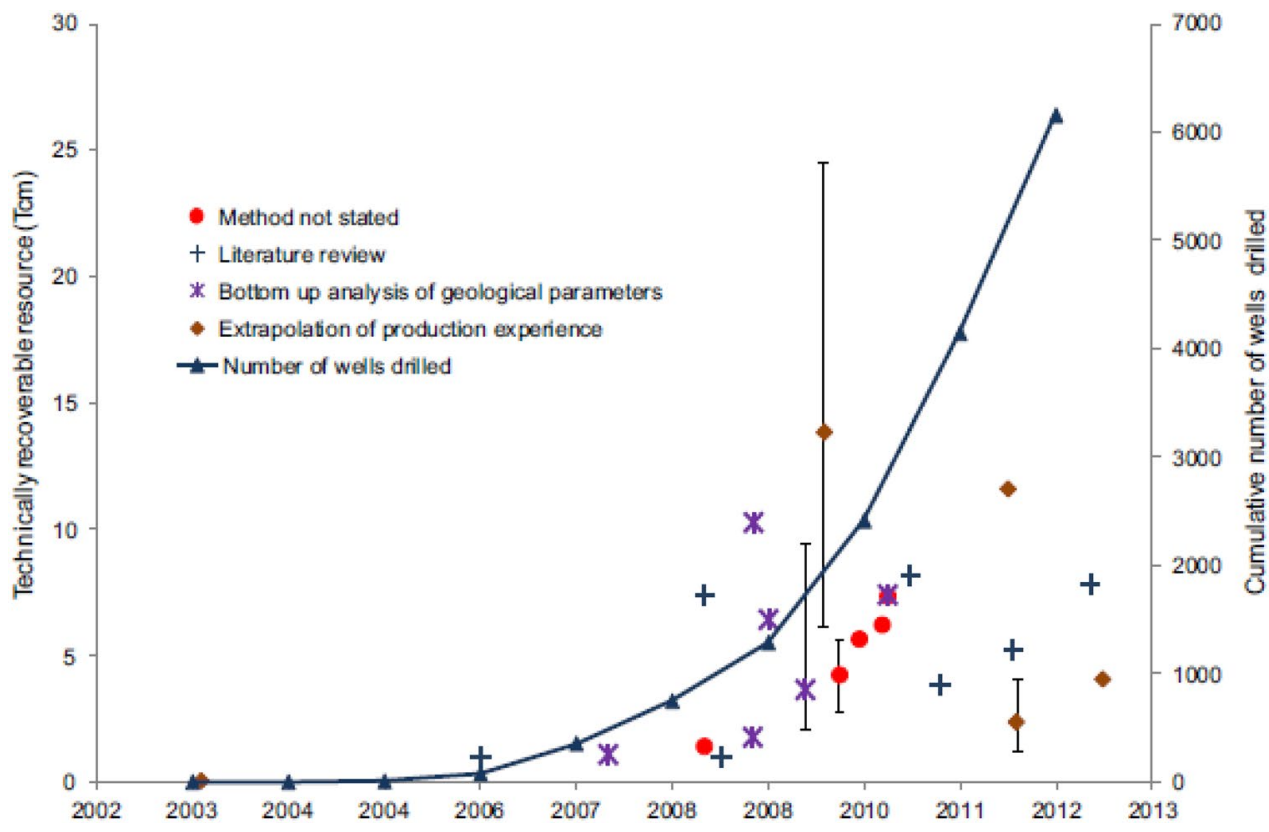




\section{Method A-Monte Carlo modification}

Previously, shale gas reserve is estimated by considering the static properties of the rock, i.e., unconventional reservoir. In fact, shale gas recovery is not only determined by the static properties of the reservoir but also determined by the design of the well or network of wells. Well geometry which includes, but not limited to lateral length and fracture spacing, will affect the amount of recoverable gas from the reservoir, therefore reserve can be estimated as the sum of maximum recovery of each well in the most optimum condition (all prospective areas drilled).

For future uncertainties' assessment and reserve classification, the reservoir is constructed as a part of the well which is a single fracture slab model, where hydraulic fracture is a compulsory completion method for developing unconventional gas reservoir. The static model of the single-slab model is built for the base case of the myriad models that will be generated to form a complete reservoir model. In building the model, there are three reservoir properties that are being set constant for each model which are fluid properties, rock-fluid flow properties and single-slab hydraulic fracture properties.

Fluid flow within rock matrix is set to be constant and adheres to Darcy flow model given the very low natural property of the rock permeability, natural, pressure-driven fluid flow will be unlikely to significantly contribute to the production of fluid. This is implied by the sensitivity analysis performed by Dong et al. (2012) which is shown in Fig. 3. Fluid relative permeability is built using Corey relative permeability model. The properties needed in generating relative permeability is assumed and the rock is assumed to be a well-sorted consolidated sandstone. The parameters
Table 1 Rock fluid parameters

\begin{tabular}{ll}
\hline Parameters & Value \\
\hline SWCON_endpoint saturation: connate water & 0.25 \\
SWCRIT_endpoint saturation: critical water & 0.25 \\
SGCON_endpoint saturation: connate gas & 0.25 \\
SGCRIT_endpoint saturation: critical gas & 0.25 \\
KRWIRO_Krw at 100\% water & 0.8 \\
KRGCL_Krg at connate liquid & 0.8 \\
Exponent for calculating Krw from KRWIRO & 3 \\
Exponent for calculating Krg from KRGCL & 3 \\
\hline
\end{tabular}

for building the rock fluid flow characteristic are given in Table 1 . The relative permeability curve generated is shown in Fig. 4.

Fluid flow in the hydraulically-made fractures, however, follows non-Darcy flows with general correlation with Forchheimer number weighting factor of 0.5 . The concept of non-Darcy flows will be discussed in Appendix A, and the properties for non-Darcy flow parameters are given in Table 2. Reservoir fluid is assumed to be the same for the entire reservoir. The fluid is assumed to maintain its single phase, gas phase, throughout production period.

Hydraulic fracturing is an essential part in developing an unconventional play. Instead of building a single horizontal well model which comprises of multiple fracture slabs, a fraction of a horizontal well, which comprises of a single fracture slab, is built. This is done to deal with uncertainty across the reservoir, where the model allows generation of a more heterogeneous reservoir model that is expected to follow real reservoir model.
Fig. 3 Spider diagram on parametrical effects on reserve assessment (Adapted from Dong et al. 2012)

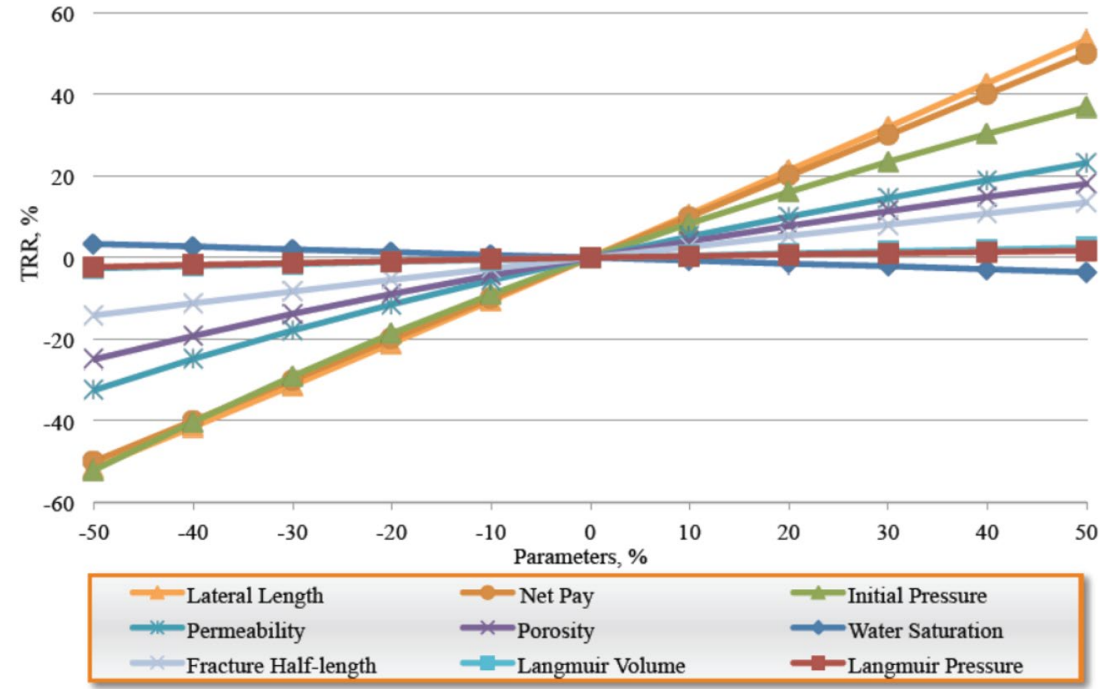


Fig. 4 General fluid relative permeability curve to be applied in model

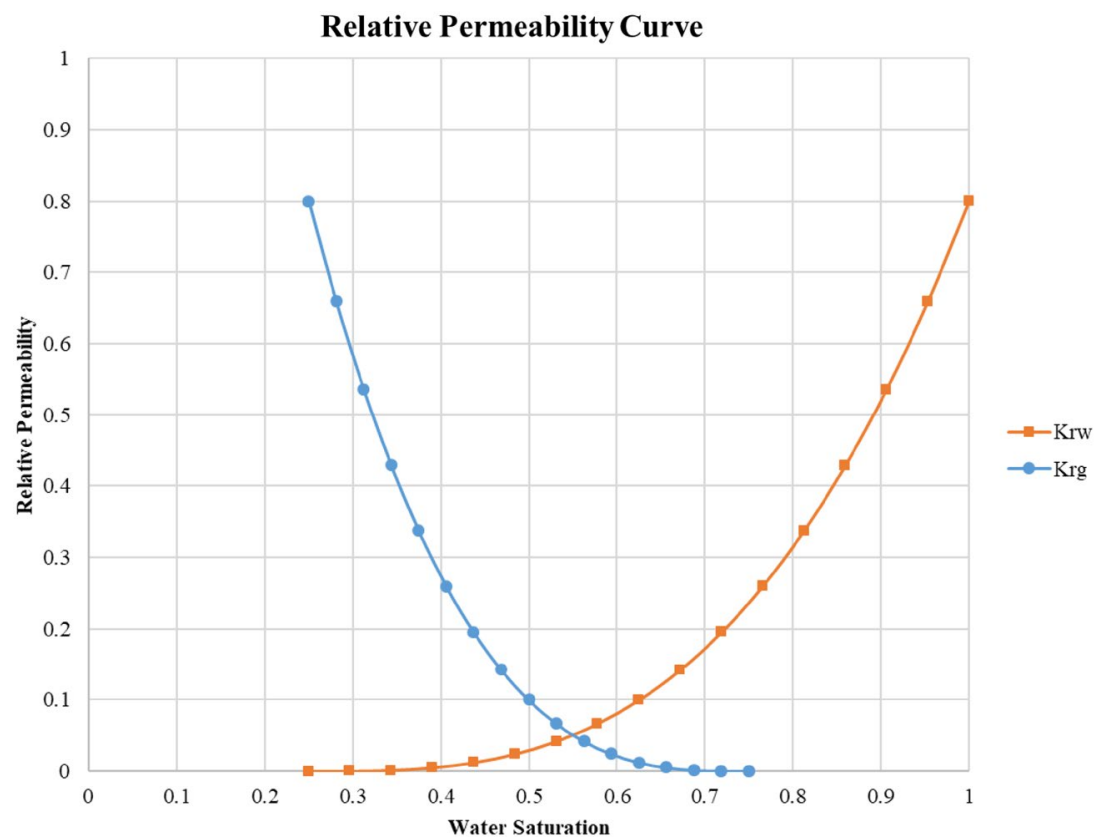

Table 2 Non-Darcy flow parameters

\begin{tabular}{lllll}
\hline Phase & $\alpha$ & $\mathrm{N} 1$ & $\mathrm{~N} 2$ & Forch $_{\max }$ \\
\hline Gas & $1.49 \times 10^{9}$ & 1.021 & 0 & 0.25 \\
Water & $1.49 \times 10^{9}$ & 1.021 & 0 & 0.25 \\
\hline
\end{tabular}

Table 3 Fracture properties

\begin{tabular}{llll}
\hline Fracture spacing, ft & 300 & 500 & 700 \\
Half length, ft & 200 & 200 & 200 \\
Fracture height. ft & $100-1000$ & $100-1000$ & $100-1000$ \\
Fracture width. ft & 0.025 & 0.025 & 0.025 \\
Fracture permeability, md & 19,616 & 19,616 & 19,616 \\
\hline
\end{tabular}

The fracture geometry follows the geometry of most fractures. Fracture model follows PKN (Perkins-Kern-Nordgren) model in which fracture maintains constant width and constant height. Fracture permeability follows proppant permeability in the given closure stress. The proppant used is assumed to be Brady sand 20/40. Three fracture spacings, 300-ft, 500-ft, and 700-ft fracture spacing, are used in determining the effect of fracture spacing on recoverable reserve. The fractures properties are given in Table 3.

Reservoir heterogeneity is also one of the major factors in a rigorous reserve estimation in a geologically uncalibrated reservoir. Aside from heterogeneity, uncertainty is one of the problems in determining hydrocarbon reserve. Uncertainty

Table 4 Summary of major shale plays in the US (Adapted from Dong et al. 2012)

\begin{tabular}{llllll}
\hline $\begin{array}{l}\text { Parameters } \\
\text { Geological age }\end{array}$ & $\begin{array}{l}\text { Barnett } \\
\text { Early /Lower } \\
\text { Carboniferous }\end{array}$ & $\begin{array}{l}\text { Eagle Ford } \\
\text { Cretaceous }\end{array}$ & $\begin{array}{l}\text { Marcellus } \\
\text { Middle Devonian }\end{array}$ & $\begin{array}{l}\text { Fayetteville } \\
\text { Early/Lower } \\
\text { Carboniferous }\end{array}$ & $\begin{array}{l}\text { Haynesville } \\
\text { Late/Upper Jurassic }\end{array}$ \\
\hline Area, acres & $3,200,000$ & $3,000,000$ & $15,000,0000$ & $2,560,000$ & $5,760,000$ \\
Depth, ft & $6500-8500$ & $5,500-14.400$ & $3,300-8,800$ & $1,200-8,000$ & $10,000-14,000$ \\
Net pay, ft & $100-600$ & $3-326$ & $45-384$ & $50-325$ & $200-300$ \\
Porosity, \% & $4-5$ & $3-12$ & $3-13$ & $2-8$ & $8-14$ \\
System permeability, $10^{-3}$ md & $0.07-5$ & $0.1-0.7$ & $0.2-0.9$ & $1-4$ & $0.5-400$ \\
Average P, psia & $3000-5,000$ & $4300-10,900$ & $2000-5100$ & $800-4000$ & $7000-10,000$ \\
Gas content, scf/ton & $60-125$ & $7-120$ & $41-148$ & $60-220$ & $100-330$ \\
Temperature, ${ }^{\circ} \mathrm{F}$ & $60-125$ & $7-120$ & $41-148$ & $60-220$ & $100-330$ \\
TOC, $\%$ & $2.4-5.1$ & $0.3-5.4$ & $2.0-8.0$ & $4.0-9.5$ & $0.5-4.0$ \\
Ro, $\%$ & $0.6-1.6$ & 1.5 & 1.25 & $2.0-5.0$ & 2.2 \\
Bulk density & 2.5 & $2.36-2.65$ & $2.30-2.60$ & N/A & $<2.57$ \\
\hline
\end{tabular}


Table 5 Uncertainty parameters' distribution

\begin{tabular}{|c|c|c|c|c|c|}
\hline Parameters & Barnett & Eagle ford & Marcellus & Fayetteville & Haynesville \\
\hline Net pay, ft & Lognormal $(200,50)$ & Lognormal $(130,50)$ & GEV $(120,70,0.1)$ & Lognormal $(150,50)$ & Lognormal $(200,50)$ \\
\hline Initial pressure, psi & Uniform $(3000,5000)$ & $\begin{array}{l}\text { Lognormal } \\
\quad(7200,1000)\end{array}$ & $\begin{array}{l}\text { Triangular } \\
(2000,4100,5100)\end{array}$ & $\begin{array}{l}\text { Triangular } \\
(800,3100,4000)\end{array}$ & Uniform $(7000,10000)$ \\
\hline $\begin{array}{l}\text { System permeability, } \\
\text { md }\end{array}$ & $\begin{array}{l}\text { Lognormal }(0.0005 \text {, } \\
0.0005)\end{array}$ & $\begin{array}{l}\text { Lognormal }(0.0004 \text {, } \\
0.001)\end{array}$ & $\begin{array}{l}\text { Lognormal }(0.0003 \text {, } \\
0.0002)\end{array}$ & $\begin{array}{l}\text { Lognormal }(0.002 \\
0.00005)\end{array}$ & $\begin{array}{l}\text { Lognormal } \\
{[0.034,0.032, \text { shift }} \\
(-0.001)]\end{array}$ \\
\hline Porosity, fraction & Uniform $(0.04,0.05)$ & invGama $(0.1,6.8)$ & $\begin{array}{l}\text { Gamma } \\
{[4,0.007, \operatorname{shift}(0.03)]}\end{array}$ & $\begin{array}{l}\text { Lognormal } \\
\quad(0.08,0.02)\end{array}$ & $\begin{array}{l}\text { Lognormal } \\
\quad(0.126,0.03)\end{array}$ \\
\hline $\begin{array}{l}\text { Water saturation. } \\
\text { fraction }\end{array}$ & Uniform $(0.25,0.43)$ & $\begin{array}{l}\text { Gamma }(3.8,0.03, \\
\operatorname{shift}(0.06))\end{array}$ & Normal $(0.26,0.08)$ & Uniform $(0.15,0.35)$ & Uniform $(0.16,0.41)$ \\
\hline Lognormal $(\mu, \sigma)$ & & & \multicolumn{3}{|c|}{ Lognormal distribution with specified mean and standard deviation } \\
\hline $\operatorname{GEV}(\mu, \sigma, \zeta)$ & & & \multicolumn{3}{|c|}{$\begin{array}{l}\text { Generalized extreme value distribution with mean, standard devia- } \\
\text { tion, and shape parameter }\end{array}$} \\
\hline $\operatorname{Gamma}(\alpha, \beta)$ & & & \multicolumn{3}{|c|}{ Gamma distribution with shape parameters and scale parameter } \\
\hline Triangular (min, most & ikely, max) & & \multicolumn{3}{|c|}{$\begin{array}{l}\text { Triangular distribution with defined minimum, most likely, and } \\
\text { maximum value }\end{array}$} \\
\hline Uniform (min, $\max )$ & & & \multicolumn{3}{|c|}{ Uniform distribution between minimum and maximum } \\
\hline
\end{tabular}

appears in every parameter in reservoir simulation, hence there is a need to assess uncertainty.

To assess the challenging heterogeneity of shale plays, analogical study is used to determine the analogous reservoir property. The US shale plays is considered to be the best shale play to be analogically studied due to the abundance of data of the shale plays. Table 4 shows the properties of five shale plays in US which are Barnett, Eagle Ford, Marcellus, Fayetteville, and Haynesville. Table 5 shows the distribution of uncertain and heterogeneous parameter for each shale play. Table 4 is used to determine which shale play is analogous to the shale play whose reserve is to be estimated. On the other hand, Table 5 is used to determine the distribution of the reservoir property in the corresponding shale play.

Uncertainty assessment involves generation and simulation of myriad models (Monte Carlo method). Models are generated with parameters that follow the respective distribution, and simulated for 30 years of production. To assess the uncertainty, three scenarios are introduced. The scenarios are the scenario in which $10 \%$ of the area is prospective (pessimistic), 50\% of the area is prospective, and $90 \%$ of the area is prospective (optimistic).

Technically recoverable reserve (TRR) is defined as the amount of recoverable hydrocarbon for a 30-year contract period. Ultimate recoverable reserve (URR) is defined as the amount of recoverable hydrocarbon for a given number of wells drilled. It is necessary to differ TRR and URR since URR is used to denote the reserve for the shale play while TRR is used to determine the economic prospect of the shale play.

In estimating the recoverable reserve, models are generated. Each model will be picked randomly to build a complete reservoir model. Models are segmented into several sections by their depth. A reservoir is built from models from different depths. Hence, reservoir depth is allocated randomly to provide heterogeneity in the reservoir model. For each depth, models are picked randomly to build the reservoir model for the corresponding depth. The amount of recoverable gas for each model selected is summed to determine the amount of recoverable gas for the entire reservoir model. The flowchart for this method is shown in appendix A.

In generating the production profile, constraint is set. In a gas contract scheme, plateau gas production rate is demanded. Hence, there is a need to set a constraint in the field production rate. For each of the cases, 90\%, 50\%, and $10 \%$ prospective area developed, the field production rate is set. Plateau gas production rate is maintained for a 25-year contract period.

Production is maintained through the use of production constraint. To increase production, a new well is drilled hence new models are picked randomly. Development is started from the shallowest formation to the deepest formation. Hence, drilling or model- picking is conducted from the shallowest formation to the deepest formation. Since each formation has a limit of well numbers, allocated randomly for each depth, drilling or model-picking activity will be moved to the next shallowest formation if the well in the previous formation has exceeded the limit. When the field production rate exceeds the production constraint, drilling activity will be stopped for the corresponding year. 
Fig. 5 Location of Bintuni basin (Adapted from Decker et al. 2011)

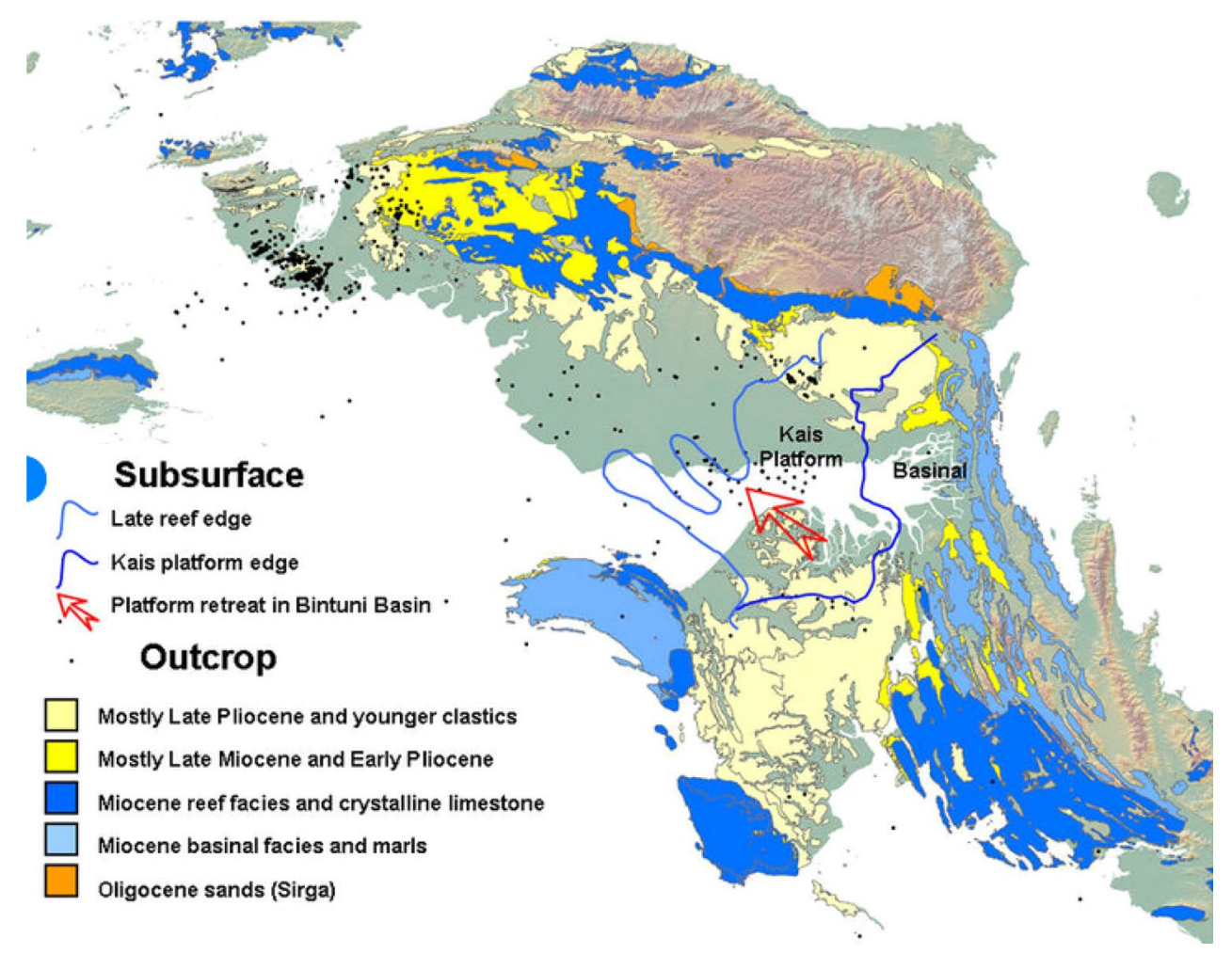

\section{Case study for method A}

\section{Bintuni basin}

Bintuni basin is a prospective basin located in the eastern side of the Bird's Head region. Figure 5 shows the location of Bintuni basin. Bintuni appears to have the best shale prospectivity in the eastern Indonesia region. Bintuni basin is bordered to the east by the Lengguru Fold/Thrust Belt. The basement consists of Upper Permian clastic sediments and shales of shallow marine origin (Aifam Group). The basin prospective area is estimated to be $3340 \mathrm{mi}^{2}$ with average thickness of $1000 \mathrm{ft}$. The depth of the reservoir varies from 5000 to $15,000 \mathrm{ft}$. The prospective aifam group is expected to be producing gas. EIA estimates the recoverable reserve of the aifam group to be 28.6 TCF from 114 TCF (Trillion Cubic Feet) original gas in place.

\section{Reserve estimation}

Since the basin is analogous to US Barnett shale in terms of geological age and fluid produced, the Barnett uncertain parameters' distribution can be used and models can be generated. Three different reserves, $10 \%$ prospective area, $50 \%$ prospective area, and $90 \%$ prospective area, are calculated
Table 6 Rate constraint for case studies

\begin{tabular}{llll}
\hline Uncertainty & \multicolumn{3}{l}{ Rate constraint, MMSCFD } \\
\cline { 2 - 4 } & $\begin{array}{l}\text { 300-ft fracture } \\
\text { spacing }\end{array}$ & $\begin{array}{l}500-\mathrm{ft} \text { fracture } \\
\text { spacing }\end{array}$ & $\begin{array}{l}700-\mathrm{ft} \\
\text { fracture } \\
\text { spacing }\end{array}$ \\
\hline 10\% prospective area & 355 & 325 & 150 \\
$50 \%$ prospective area & 1750 & 1600 & 700 \\
$90 \%$ prospective area & 3200 & 3000 & 1300 \\
\hline
\end{tabular}

for each three different fracture-spacing scenarios. Table 5 shows the result of the reserve estimation.

\section{Production profile forecast for each constraint}

Production profile is forecasted using the available generated models. Gas contract rate constraint for each case is given in Table 6. The forecasted production profile is shown in Fig. 6.

\section{Results estimation}

EIA estimates 28.6 TCF ultimate recoverable reserve from the original gas in place of 114 TCF. Table 7 shows the result obtained from the method proposed. The similar 

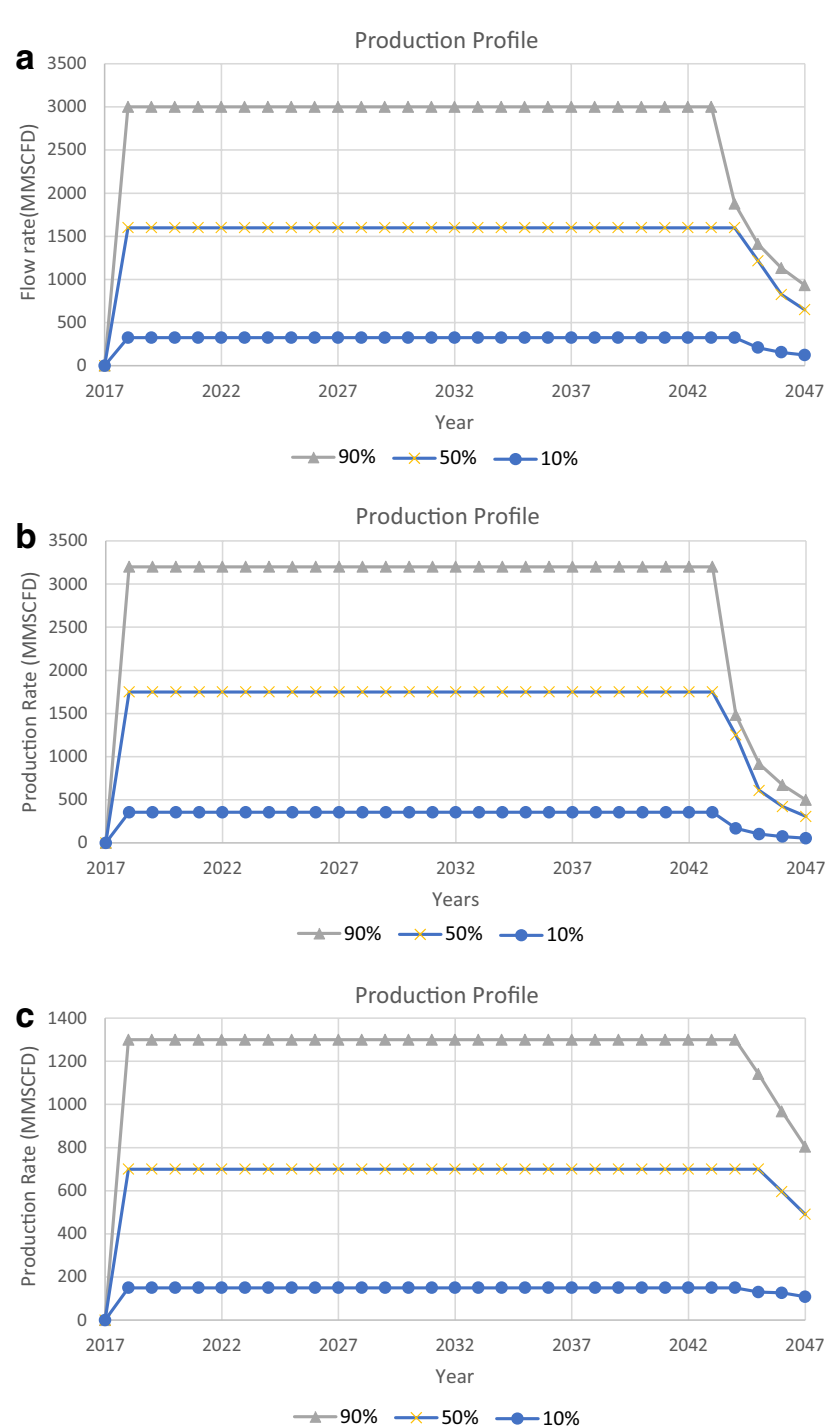

Fig. 6 a Production profile forecast for $300-\mathrm{ft}$ well spacing. b Production profile forecast for 500 -ft well spacing. c Production profile forecast for $700-\mathrm{ft}$ well spacing

number is achieved when developing Bintuni basin with 700 -ft fracture spacing with $90 \%$ prospective area drilled. The expected recoverable gas, technically recoverable reserve, for 30 -year production period is $13.9 \mathrm{TCF}$ from the forecasted production profile. The best recovery is achieved with 300 -ft fracture spacing which gives $28.89 \%$ of recovery factor. The result shows that different fracture geometry, i.e., different fracture spacing, will result in different recoverable reserve. This is due to the fact that the fluid is initially unable to flow, hence artificial fracture provides significant effect on the fluid production. Previous reserve estimation considers only the static parameters of the reservoir
Table 7 Simulation results

\begin{tabular}{|c|c|c|c|}
\hline \multicolumn{4}{|l|}{$300-\mathrm{ft}$ fracture spacing } \\
\hline Prospective area developed & $90 \%$ & $50 \%$ & $10 \%$ \\
\hline Recovered gas in contract period, TCF & 31.7 & 17.6 & 3.5 \\
\hline Ultimate recovery, TCF & 36.4 & 20.2 & 4.0 \\
\hline OGIP, TCF & 126 & 69.9 & 14.2 \\
\hline RF until end of contract, $\%$ & 25.16 & 25.18 & 24.79 \\
\hline RF until ultimate recovery, $\%$ & 28.89 & 28.89 & 28.50 \\
\hline Well count & 34,227 & 19,015 & 3803 \\
\hline \multicolumn{4}{|l|}{$500-\mathrm{ft}$ fracture spacing } \\
\hline Prospective area developed & $90 \%$ & $50 \%$ & $10 \%$ \\
\hline Recovered gas in contract period, TCF & 30.4 & 16.8 & 3.4 \\
\hline Ultimate recovery, TCF & 33.0 & 18.3 & 3.7 \\
\hline OGIP, TCF & 126 & 69.9 & 14.2 \\
\hline RF until end of contract, $\%$ & 24.12 & 24.03 & 23.84 \\
\hline RF until ultimate recovery, $\%$ & 26.19 & 26.18 & 25.98 \\
\hline Well count & 34,218 & 19,010 & 3802 \\
\hline \multicolumn{4}{|l|}{$700-\mathrm{ft}$ fracture spacing } \\
\hline Prospective area developed & $90 \%$ & $50 \%$ & $10 \%$ \\
\hline Recovered gas in contract period, TCF & 13.9 & 7.6 & 1.6 \\
\hline Ultimate recovery, TCF & 32.7 & 18.1 & 3.6 \\
\hline OGIP, TCF & 126 & 69.9 & 14.2 \\
\hline RF until end of contract, $\%$ & 10.99 & 10.79 & 11.37 \\
\hline RF until ultimate recovery, $\%$ & 25.93 & 25.88 & 25.94 \\
\hline Well count & 38,005 & 19,006 & 3798 \\
\hline
\end{tabular}

in estimating the recoverable reserve. This will lead to a probable erroneous result. Hence, future reserve estimation has to consider hydraulic fracture geometry beside static reservoir parameters.

\section{Method B-SRV-based approach}

When considering production of shale gas field, one of the primary concerns is the estimation of initial gas in place. In the case of shale gas reservoirs - unlike in conventional or tight sand gas reservoirs where gas is stored as free gas-a huge fraction of gas in place is stored both as free gas in matrix pores and fractures and as adsorbed gas on the surface of matrix particles by adsorption mechanism. Comprehensive evaluation of well horizontal length and fracture spacing, length, as well as density plays an important role to determine the shale gas field performance. The volume defined by transverse fractures from horizontal wellbore is referred as stimulated reservoir volume (SRV) (Mayerhofer, et al., 2008). Geometrical fracture system of SRV can be 
Table 8 Scenarios for lateral length sensitivity run

\begin{tabular}{ll}
\hline Scenario & $\begin{array}{l}\text { Well-lateral } \\
\text { length }(\mathrm{ft})\end{array}$ \\
\hline Base case & 3000 \\
Case 1-1 & 3900 \\
Case 1-2 & 4500 \\
Case 1-3 & 5400 \\
Case 1-4 & 6300 \\
Case 1-5 & 7200 \\
\hline
\end{tabular}

generated with the interaction of hydraulic fractures and preexisting natural fractures.

In the light of data limitations provided in real-life shale field, this study demonstrates a reasonable approach to estimate SRV by early quantification of the well's drainage volume (DV). The DV of shale gas reservoir can be determined through pressure drawdown analysis at the time when the fluid flow has reached its boundaries (pseudo-steady state). In this paper, a correlation to estimate SRV is established from DV analysis that accounts for well and hydraulic fracturing parameters and the pressure profile during pseudosteady period of a shale production simulated in Haynesville shale gas play in North America.

Simulated Reservoir Volume (SRV) in essence is the complex network of structures created by fractures that represents the total volume of reservoir rock that has been hydraulically fractured. SRV is created in the formation and modelled by accounting a combination of many mechanisms such as the presence of natural fractures and their interaction with the created fractures from hydraulic fracturing, stress anisotropy, and fluid viscosity (Cipolla et al. 2008).

To calculate the SRV for cases which the well and hydraulic fracturing parameters are of sensitivity variables, this paper will only discuss two methods: (1) analytical method using pressure drawdown analysis test and (2) planar model simulation result using CMG. As for method (1), certain adjustment is required to convert the obtained value of DV into SRV value. This is particularly of importance because method (1) assesses the volume to be uniformly drained based on well performance, while SRV concept is generally assessed geometrically from the shearing and deformation that occur in the reservoir rock so the results of both methods are rarely deemed to be similar in unconventional reservoirs (Maxwell 2013).

Estimation of DV of a well is accomplished by pressure drawdown analysis, or also known as reservoir limit testing. The calculation requires the slope of the plotted bottomhole pressure versus time during a period when the flow has followed a pseudo-steady state behavior, indicated by the pressure decline that varies linearly with time $(\mathrm{d} P / \mathrm{d} t=$ constant $)$. The drainage volume is mathematically expressed by the following equation:
Table 9 Scenarios for fracturespacing sensitivity run

Table 10 Scenarios for fracture half-length sensitivity run

\begin{tabular}{lll} 
Table 11 Reservoir characteristics of all models & \\
\hline Reservoir characteristics & Value & Unit \\
\hline Rock compressibility & $9.9974 \mathrm{e}-007$ & $1 / \mathrm{psi}$ \\
Reservoir temperature & 320 & $\mathrm{~F}$ \\
Reference pressure & 9883 & $\mathrm{Psi}$ \\
Reference depth & 11,231 & $\mathrm{Ft}$ \\
Net pay & 270 & $\mathrm{Ft}$ \\
Matrix permeability & 0.00017 & $\mathrm{Md}$ \\
Fracture permeability & $8.3 \mathrm{e}-006$ & $\mathrm{Md}$ \\
Matrix porosity & 0.02 & Fraction \\
Fracture porosity & 0.0014 & Fraction \\
\hline
\end{tabular}

$V_{\mathrm{p}}=C \frac{q B}{\beta C_{\mathrm{t}}}$,

$C$ value of 0.0418 is a constant used to properly convert all the parameters into field unit, the value is typically used as a rule of thumb. The value of the constant depends on the type of reservoir fluid. The $\beta$ value represents the slope of the plot of pressure versus time.

Determination and optimization of SRV may use various tools such as rate transient analysis (RTA) and numerical simulations (Shahkarami et al. 2017). In this particular 
Table $12 \mathrm{C}$ values for all sensitivity scenarios

\begin{tabular}{llll}
\hline Lateral length (ft) & Spacing $(\mathrm{ft})$ & Half length $(\mathrm{ft})$ & $\mathrm{C}$ \\
\hline 3000 & 100 & 250 & 375.147 \\
3000 & 200 & 250 & 375.147 \\
3000 & 250 & 250 & 375.147 \\
3000 & 300 & 250 & 222.051 \\
3000 & 400 & 250 & 222.051 \\
3000 & 500 & 250 & 243.264 \\
3000 & 600 & 250 & 278.763 \\
3000 & 600 & 400 & 246.504 \\
3000 & 600 & 450 & 203.994 \\
3000 & 600 & 500 & 217.587 \\
3000 & 600 & 550 & 199.111 \\
3000 & 600 & 600 & 216.357 \\
3900 & 600 & 250 & 232.190 \\
4500 & 600 & 250 & 184.134 \\
5400 & 600 & 250 & 170.533 \\
6300 & 600 & 250 & 166.734 \\
7200 & 600 & 250 & 166.251 \\
\hline
\end{tabular}

Table 13 DV from lateral length sensitivity

\begin{tabular}{ll}
\hline Scenario & $\begin{array}{l}\text { Drainage volume } \\
\left(\mathrm{SCF} \times 10^{10}\right)\end{array}$ \\
\hline Base case & 18.05 \\
Case $1-1$ & 27.42 \\
Case $1-2$ & 39.09 \\
Case 1-3 & 46.70 \\
Case 1-4 & 57.40 \\
Case 1-5 & 61.73 \\
\hline
\end{tabular}

study, commercial simulation package of Computer Media Group (CMG-BUILDER) and GEM Compositional Model (Computer Modelling Group 2015) were used. The drainage area is divided into 1050 grid blocks with block size of 150 feet by 100 feet. The top of reservoir is at 11,231 feet and net pay thickness is 270 feet, with 90 feet allotted into each of the three layers that make up the model in K-direction. The reservoir contains dry gas, which comprises mainly methane and smaller fractions of ethane, propane, and nitrogen.

Wells are drilled horizontally with varied length and perforated at the middle layer of the three layers of Haynesville reservoir model. Grid blocks were refined to simulate planar fractures created perpendicular to the wellbore direction. Important fracture parameters such as fracture half-length and spacing were to be sensitivity variables to find out the optimum SRV and production performance from 2018 for 40 years until 2058 with the set constraint of 250 psi bottom
Table 14 DV from fracture-spacing sensitivity

\begin{tabular}{ll}
\hline Scenario & $\begin{array}{l}\text { Drainage volume } \\
\left(\mathrm{SCF} \times 10^{10}\right)\end{array}$ \\
\hline Base case & 18.05 \\
Case 2-1 & 24.54 \\
Case 2-2 & 35.17 \\
Case 2-3 & 31.95 \\
Case 2-4 & 35.91 \\
Case 2-5 & 34.00 \\
Case 2-6 & 30.18 \\
\hline
\end{tabular}

Table 15 DV from fracture half-length sensitivity

\begin{tabular}{ll}
\hline Scenario & $\begin{array}{l}\text { Drainage volume } \\
\left(\mathrm{SCF} \times 10^{10}\right)\end{array}$ \\
\hline Base case & 18.05 \\
Case 3-1 & 37.68 \\
Case 3-2 & 47.11 \\
Case 3-3 & 55.79 \\
Case 3-4 & 62.95 \\
Case 3-5 & 70.62 \\
\hline
\end{tabular}

hole pressure limit. Illustrated in Fig. 6 is the example of planar hydraulic fracturing design.

The main objective of this study is analysis of SRV from model and drainage volume relationship based on well and hydraulic fracturing parameters in Haynesville shale play, assessment of those parameters-lateral length, fracture spacing, and fracture half-length-is necessary to see the affected changes. Tables 8, 9 and 10 summarize cases run for each of the parameter, and values that were of scenario inputs chosen based on common practices in US.

This study followed the workflow illustrated in Appendix B. The first two steps include building the reservoir model as well as defining what are the important well parameters and their value ranges. The process continues with the assessment and calculation of SRV and DV of all sensitivity cases. Effects of various sensitivity values are going to be analyzed and in the DV analysis, a mathematical correlation will be established from multivariate regression of calculated results. Coupling the DV with SRV analysis, comparison of both values will be used to establish a mathematical correlation modification to get the SRV from DV. The results and calculation base of the models can be seen on Tables 11, $12,13,14,15$, and 16 .

The aim of this study is to analyze the relationship between SRV from hydraulic fracturing model and DV from drawdown test to obtain a correlation for SRV calculation, the analysis is broken down into the following sections: 


\section{Model simulation results}

In the first step of calculation, various simulation scenarios of three wells and hydraulic fracturing sensitivity parameters were run to obtain the values of SRV. The shale reservoir was simulated to produce for 40 years starting from January 2018 to January 2058. Production constraint for the simulation is summarized in Table 17.

\section{Well-lateral length sensitivity}

Table 18 shows the effect of various well-lateral lengths to SRV with other hydraulic fracturing parameters being held constant. Longer well-lateral length will result in the increasing value of SRV created along the well as the contact to reservoir also increases.

\section{Fracture spacing sensitivity}

Table 19 shows the SRV result of fracture spacing sensitivity and gives away the relationship between fracture spacing and its impact on SRV with other parameters being held constant. As the spacing becomes denser, SRV also increases. Although it is interesting to note that at certain points, reduction in fracture spacing does not result in any increment in SRV. This is mainly due to the fact that the area drained by the created fracture of the denser spacing is within the drainage area of the sparser spacing, thus no significant increase in SRV can be observed.

\section{Fracture half-length sensitivity}

Based on the result given in Table 20, as the fracture halflength becomes longer, the SRV also increases. However, as is the case with fracture-spacing sensitivity, increase in halflength does not always translate into significant increase in SRV, particularly when the half-length increment is not that long-where in this case the difference is only $50 \mathrm{ft}$. This means that fracture propagation resulted from $50-\mathrm{ft}$ shorter half-length more or less covers the same area of the $50-\mathrm{ft}$ longer half-length. Despite the relatively increasing trend of SRV along with the increase in fracture half-length, one must bear in mind that in real field application, the economic and technical feasibility of half-length elongation needs to be taken into account.

\section{Pressure drawdown test results}

Following the running of simulation to get the SRV values, the next calculation step taken was to calculate the drainage volume using reservoir limit testing. Fundamental equation that was of use in the drawdown analysis is as follows:
Table 16 DV for correlation modification

\begin{tabular}{lllll}
\hline No & $\begin{array}{l}\text { Lateral } \\
\text { length }(\mathrm{ft})\end{array}$ & Spacing $(\mathrm{ft})$ & $\begin{array}{l}\text { Half length } \\
(\mathrm{ft})\end{array}$ & $\begin{array}{l}\text { Drainage volume } \\
\left(\mathrm{SCF} \times 10^{10}\right)\end{array}$ \\
\hline 1 & 3000 & 250 & 250 & 35.91 \\
2 & 3000 & 400 & 250 & 35.17 \\
3 & 3000 & 500 & 250 & 24.54 \\
4 & 3000 & 600 & 250 & 18.05 \\
5 & 3000 & 600 & 400 & 37.68 \\
6 & 3000 & 600 & 450 & 47.11 \\
7 & 3000 & 600 & 500 & 55.79 \\
8 & 3000 & 600 & 550 & 62.95 \\
9 & 3000 & 600 & 600 & 70.62 \\
10 & 3900 & 600 & 250 & 27.42 \\
11 & 4500 & 600 & 250 & 39.09 \\
12 & 5400 & 600 & 250 & 46.70 \\
13 & 6300 & 600 & 250 & 57.40 \\
14 & 7200 & 600 & 250 & 61.73 \\
\hline
\end{tabular}

$\mathrm{IGIP}=C \frac{q}{\beta C_{\mathrm{t}}}$,

with simple place substitution, the above equation can be transformed into:

$C=\frac{\operatorname{IGIP} \beta C_{\mathrm{t}}}{q}$.

Seeing that this study focuses on tight shale reservoir, the gas in place is the volume of fractured rock only as the possibility of recovering the gas in tight formation is almost impossible without any sort of stimulation towards the rock. As such, to determine the $\mathrm{C}$ value, the term IGIP is replaced by SRV instead - of which the values were obtained from model simulation - to better approach the real stimulated volume created by fractures. The equation used is then given below:

$C=\frac{\operatorname{SRV} \beta C_{t}}{q}$

After SRV values for each case of sensitivity scenarios were obtained, the previous simulation results were used to plot bottomhole pressure versus time throughout the 40-year production period. For every pressure profile, linear slope of the region in which flow has reached pseudo-steady state was calculated. Basic principle of linearity is applied to determine the slope.

$\beta=\left|\frac{P_{\mathrm{wf} 1}-P_{\mathrm{wf} 2}}{t_{1}-t_{2}}\right|$.

Table 21 shows the calculated slope values for every scenario. 
Table 17 Simulation constraint

\begin{tabular}{lll}
\hline Constraint & Value & Unit \\
\hline$q_{\text {prod }}$ & 200,000 & SCF/day \\
$P_{\text {wf }}$ & 250 & psi \\
\hline
\end{tabular}

In the determination of total compressibility value, Eq. 2 was used. As for this study, shale reservoir only contains gas $(\mathrm{Sg}=1)$ because the gas-water contact $(\mathrm{GWC})$ is not modelled. Aquifer location lies deeper down the target reservoir so it is assumed that the flow of water phase has yet to reach the created fractures.

Once the values for all required parameters to determine $\mathrm{C}$ had been obtained, the next step of calculation would be to figure out the $\mathrm{C}$ values for all sensitivity scenarios. From there on, using Data Analysis Tool of Excel to carry out multivariate regression analysis on $\mathrm{C}$ values to model the relationship between $\mathrm{C}$ constant and other well and hydraulic fracturing parameters can be a solution for simple reserve estimation based on fracture development.

Correlation that models the relationship between $\mathrm{C}$ and well and fracture parameters is expressed as follows:

$$
\begin{aligned}
C= & 509.0892019-0.022969665 L-0.280922434 \mathrm{HFS} \\
& -0.110621578 X_{f},
\end{aligned}
$$

where term $L, H F S$, and $X_{\mathrm{f}}$ represent well-lateral length, fracture spacing, and fracture half-length, respectively. $R^{2}$ value for this equation is 0.9199 .

Substituting the above equation into Eq. 2 and referring to the initial definition of SRV in drawdown analysis being DV, the DV equation now becomes:

$$
\begin{aligned}
\mathrm{DV} & =(509.0892019-0.022969665 L-0.280922434 \mathrm{HFS} \\
& \left.-0.110621578 X_{\mathrm{f}}\right)\left(\frac{q}{\beta C_{\mathrm{t}}}\right) .
\end{aligned}
$$

Using the above equation, DV values of sensitivity scenarios for each well and fracture parameters were calculated and results are summarized in the Tables 18, 19 and 20.

Table 18 SRV from well-lateral length sensitivity
Table 19 SRV from fracturespacing sensitivity

Table 20 SRV from fracture half-length sensitivity

\section{Result comparison between SRV and DV}

Reasonable estimate of DV can be calculated using the volume derived from the basic reservoir limit testing equation. However, when DV results were compared with the SRV results from reservoir simulation model, different values were observed. This phenomenon confirms the theory that magnitude DV is not necessarily always equal to that of SRV or vice versa. Comparisons between SRV and DV for all sensitivity parameters are graphically summarized throughout Figs. 7, 8, 9, and 10.

In spite of the differing results between SRV and DV, from the figures it can be seen that for the sensitivity parameter of well-lateral length and -half length, both SRV and DV show relatively proportional trends. When there is an increase in SRV, DV tends to increase as well. However, this is not the case for fracture-spacing sensitivity results, where SRV and DV trends are different from one another. The difference is particularly palpable when the SRV supposedly does not change significantly (illustrated by the flat trend) but the DV result shows a downturn in its trend.

Recognizing the limitation of DV correlation used in the calculation-specifically when the observed parameter is fracture spacing-in the correlation modification of DV into SRV, the DV results of 300, 200, and $100 \mathrm{ft}$ spacing were not included. Another thing to note when using DV correlation is that when there is a downward trend of volume when theoretically it is supposed to increase, then the trend might

\begin{tabular}{ll}
\hline Scenario & $\begin{array}{l}\text { Stimulated res- } \\
\text { ervoir volume } \\
\left(\mathrm{SCF} \times 10^{10}\right)\end{array}$ \\
\hline Base case & 3.90 \\
Case 2-1 & 5.02 \\
Case 2-2 & 7.17 \\
Case 2-3 & 7.17 \\
Case 2-4 & 1.43 \\
Case 2-5 & 1.43 \\
Case 2-6 & 1.43 \\
\hline
\end{tabular}

\begin{tabular}{ll}
\hline Base case & 3.90 \\
Case 3-1 & 6.45 \\
Case 3-2 & 6.45 \\
Case 3-3 & 7.88 \\
Case 3-4 & 7.88 \\
Case 3-5 & 9.32 \\
\hline
\end{tabular}

\begin{tabular}{ll}
\hline Scenario & $\begin{array}{l}\text { Stimulated res- } \\
\text { ervoir volume } \\
\left(\mathrm{SCF} \times 10^{10}\right)\end{array}$ \\
\hline Base case & 3.90 \\
Case 1-1 & 5.02 \\
Case 1-2 & 5.73 \\
Case 1-3 & 6.45 \\
Case 1-4 & 7.88 \\
Case 1-5 & 8.60 \\
\hline
\end{tabular}


Fig. 7 Example of refined grid blocks of planar hydraulic fracturing design

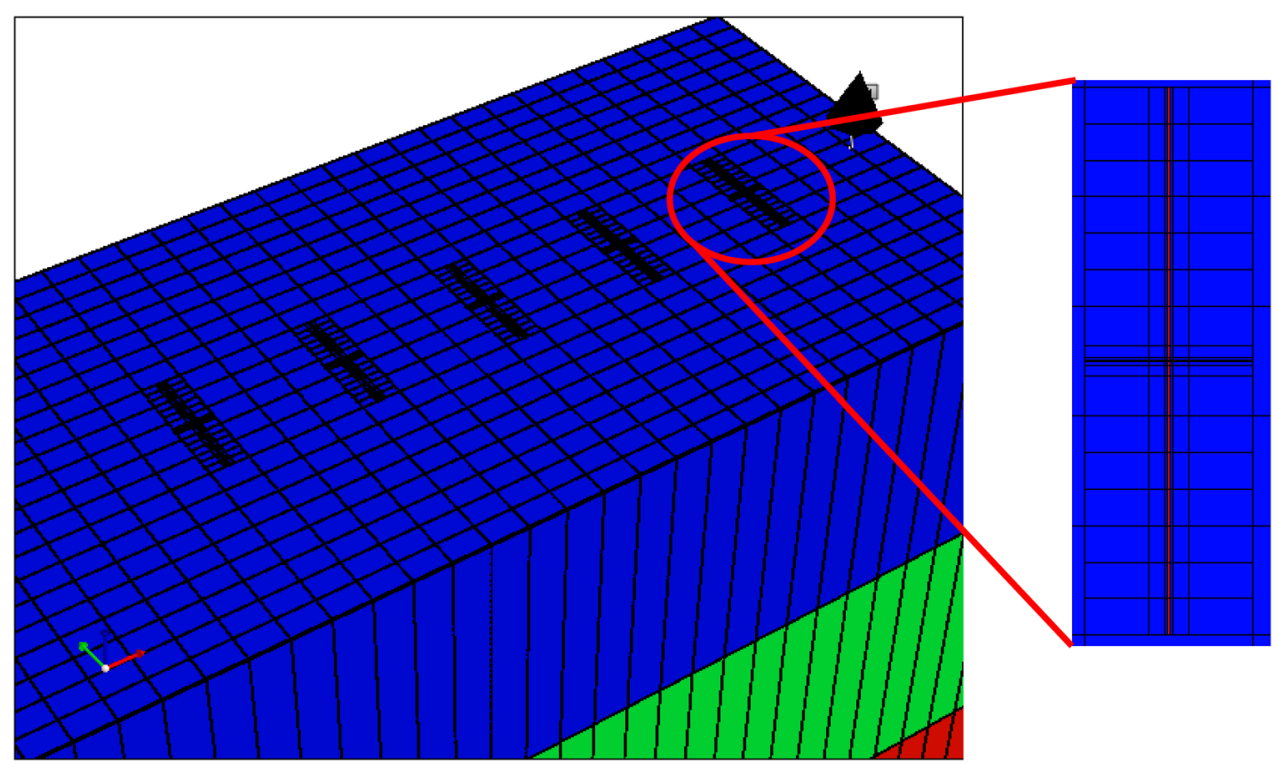

serve as an indication that there is no significant increment in volume despite the change in fracture parameter value.

Once the SRV and DV values were calculated, they were to be plotted in one graph with DV being the value for $x$ axis and SRV for $y$ axis. The plot is illustrated by Fig. 11. From this plot, the following mathematical relationship between SRV and DV can be obtained (Fig. 12).

$$
\mathrm{SRV}=8.6637 \mathrm{DV}-2 \times 10^{11}
$$

Equation 8 can now be used to estimate SRV from DV calculation using Eq. 7 that accounts for well and hydraulic fracturing parameters and the pressure profile during pseudo-steady period of a shale production simulated in Haynesville shale gas play in North America (Fig. 13).

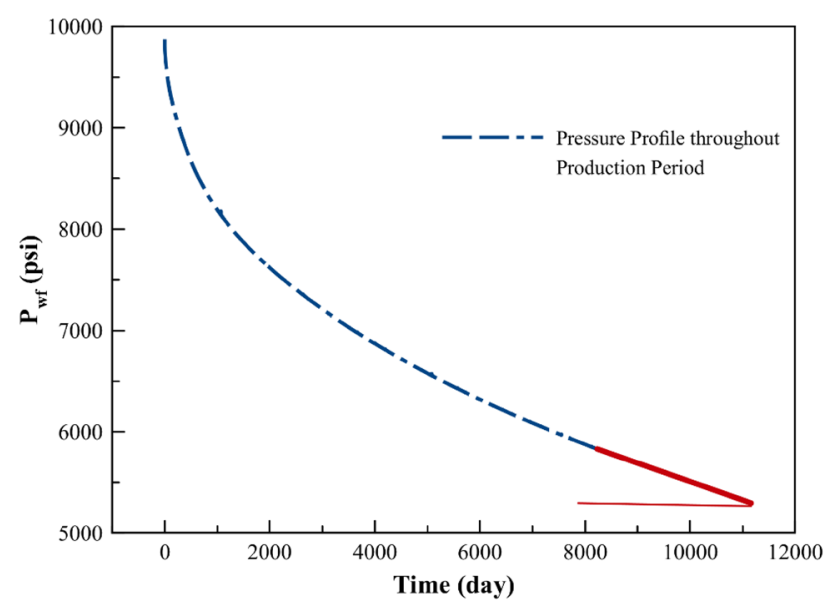

Fig. 8 Bottomhole pressure profile throughout production period

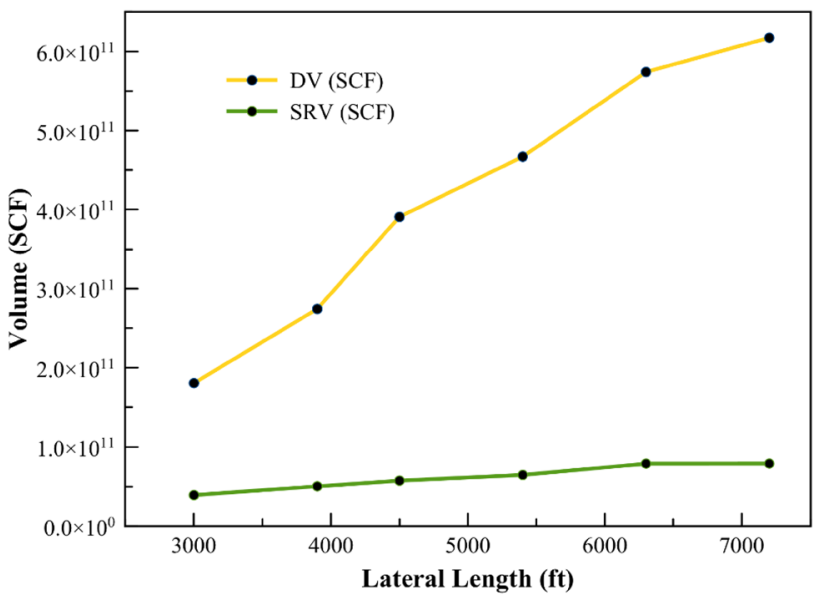

Fig. 9 SRV-DV comparison of lateral length sensitivity

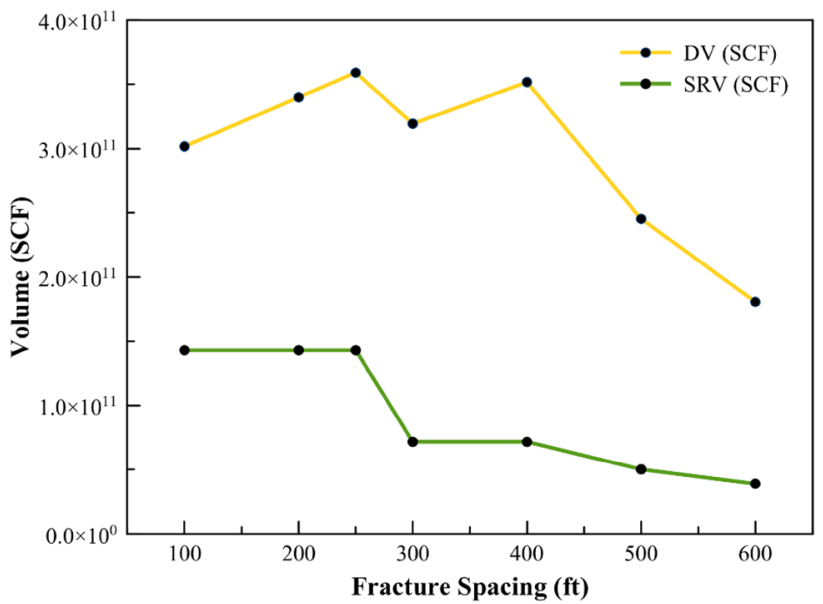

Fig. 10 SRV-DV Comparison of fracture-spacing sensitivity 
Table 21 Slope values for all sensitivity scenarios

\begin{tabular}{llll}
\hline $\begin{array}{l}\text { Lateral length } \\
(\mathrm{ft})\end{array}$ & Spacing $(\mathrm{ft})$ & $\begin{array}{l}\text { Half } \\
\text { length }(\mathrm{ft})\end{array}$ & Slope (psi/day) \\
\hline 3000 & 100 & 250 & -0.19115 \\
3000 & 200 & 250 & -0.19115 \\
3000 & 250 & 250 & -0.19115 \\
3000 & 300 & 250 & -0.22629 \\
3000 & 400 & 250 & -0.22629 \\
3000 & 500 & 250 & -0.35415 \\
3000 & 600 & 250 & -0.52179 \\
3000 & 600 & 400 & -0.27912 \\
3000 & 600 & 450 & -0.23099 \\
3000 & 600 & 500 & -0.20158 \\
3000 & 600 & 550 & -0.18446 \\
3000 & 600 & 600 & -0.16960 \\
3900 & 600 & 250 & -0.33803 \\
4500 & 600 & 250 & -0.23456 \\
5400 & 600 & 250 & -0.19310 \\
6300 & 600 & 250 & -0.15447 \\
7200 & 600 & 250 & -0.14119 \\
\hline
\end{tabular}

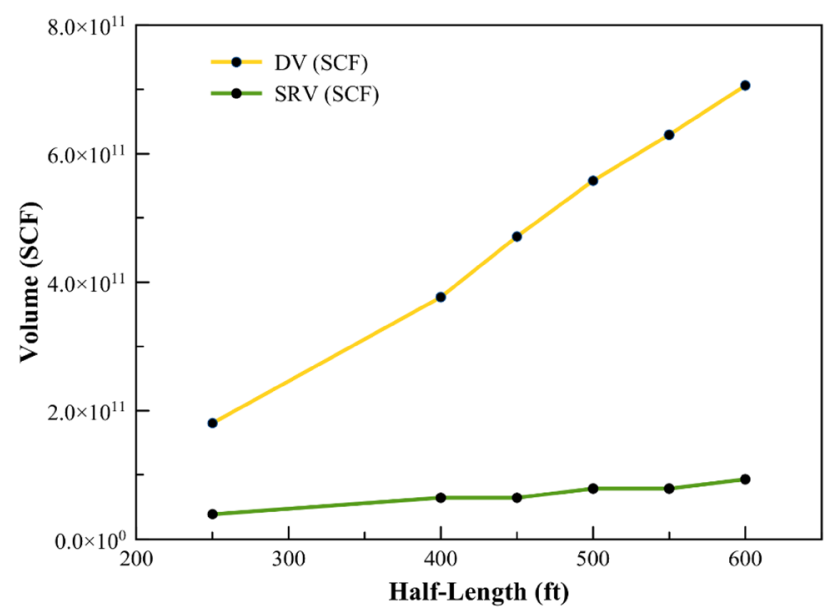

Fig. 11 SRV-DV Comparison of fracture half-length sensitivity

\section{Conclusion}

Two new methods for reserves' classification and estimation have been developed. The first method is based on Monte Carlo adaptation, the proposed method can be used to estimate unconventional hydrocarbon reserve, based on different hydraulic fracture-based development scenarios will result in different recoverable reserve. This method is also beneficial due to future production profile and can be forecasted through the use of the proposed method.

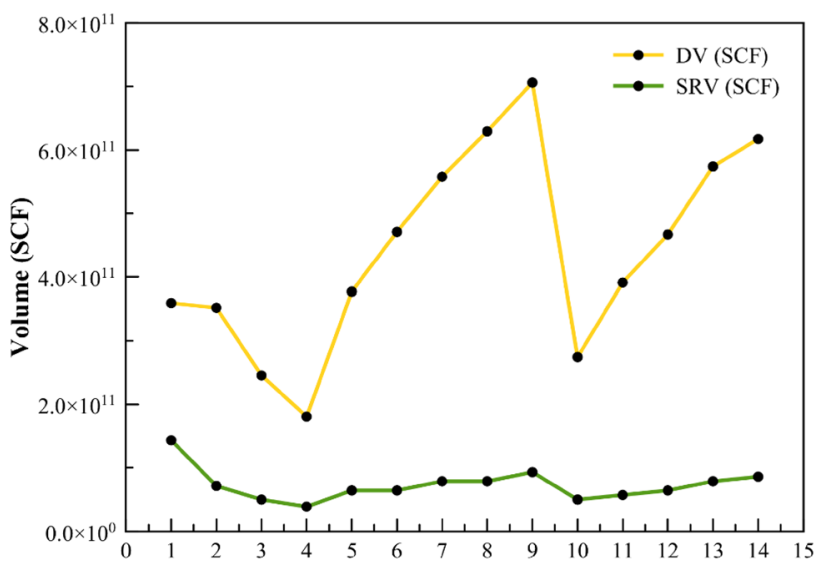

Fig. 12 SRV and DV for correlation modification

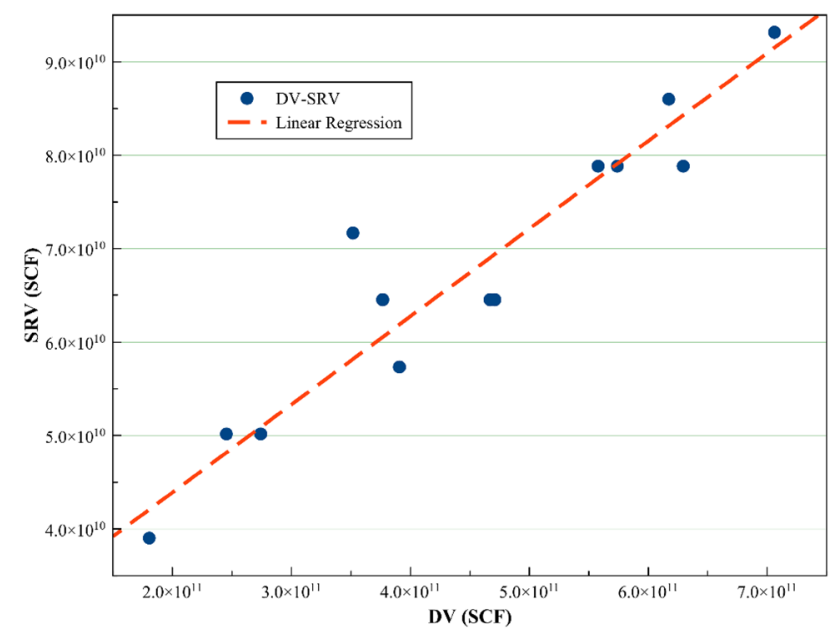

Fig. 13 SRV-DV linear regression

The second method is based on well-testing data. Given the limited availability of data in the field to calculate SRV thoroughly, this method provides a correlation to quickly estimate DV of a hydraulically fractured well in shale reservoir by utilizing the simple pressure drawdown analysis and another correlation that serves as the correction factor to convert the obtained DV into SRV value. Both the DV correlation and the modifying correlation were obtained from multivariate and linear regression of values from prior sensitivity runs, with $\mathrm{R}^{2}$ value of $91.99 \%$ and $94.82 \%$ for DV multivariate regression and SRV conversion linear regression, respectively. However, it is worth noting that since the model used in the sensitivity runs the incorporated properties of Haynesville Shale, correlations given in this paper best estimate SRV of hydraulically fractured well in shale reservoir with properties that are about relatively similar in values to that of Haynesville. Otherwise, the resulted SRV 
estimation will likely suffer inaccuracies to some degree and further adjustments need to be made.

Open Access This article is distributed under the terms of the Creative Commons Attribution 4.0 International License (http://creativeco mmons.org/licenses/by/4.0/), which permits unrestricted use, distribution, and reproduction in any medium, provided you give appropriate credit to the original author(s) and the source, provide a link to the Creative Commons license, and indicate if changes were made.

\section{Appendix A}

Flowchart of method A.

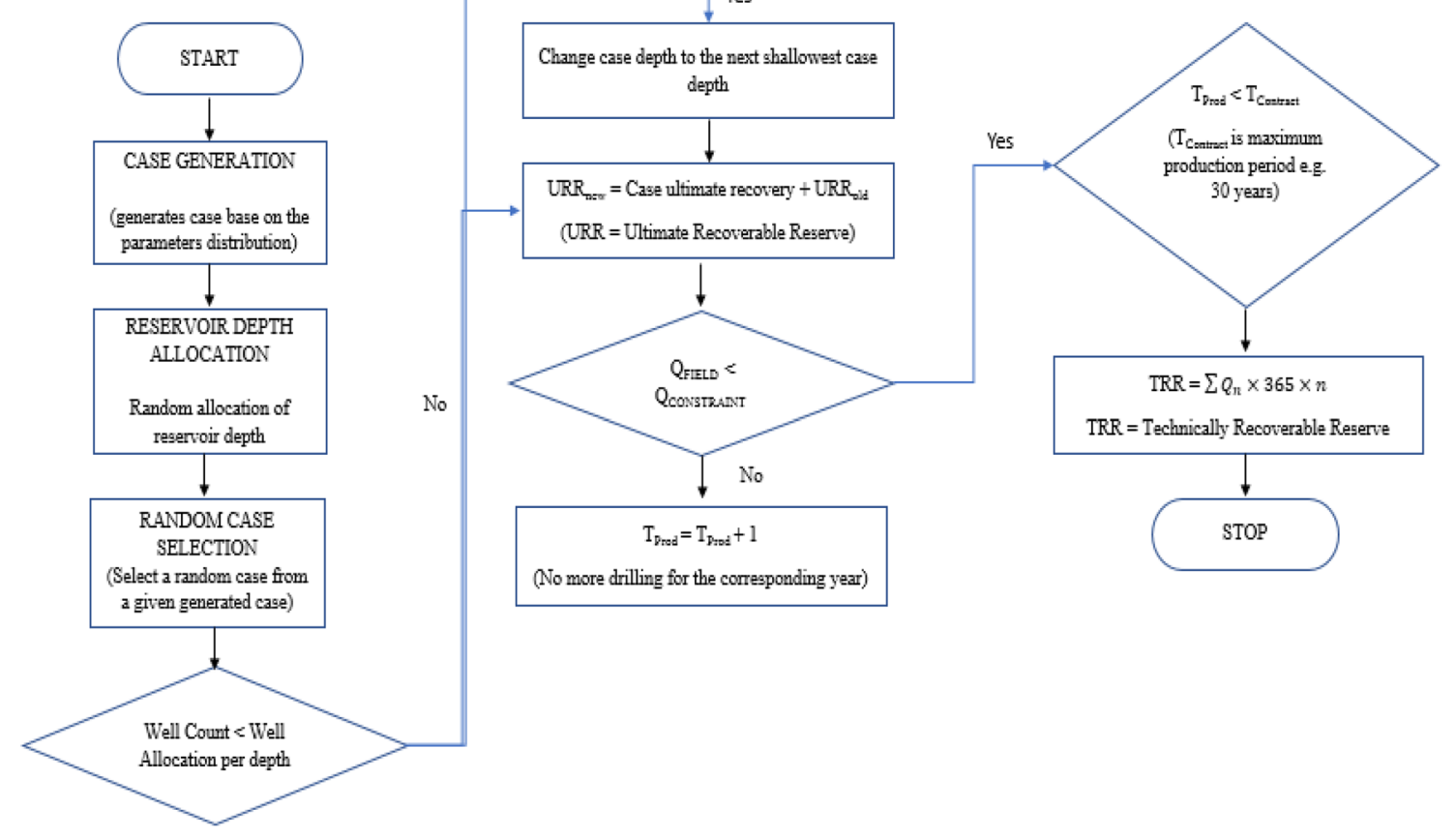




\section{Appendix B}

Flowchart of method B.

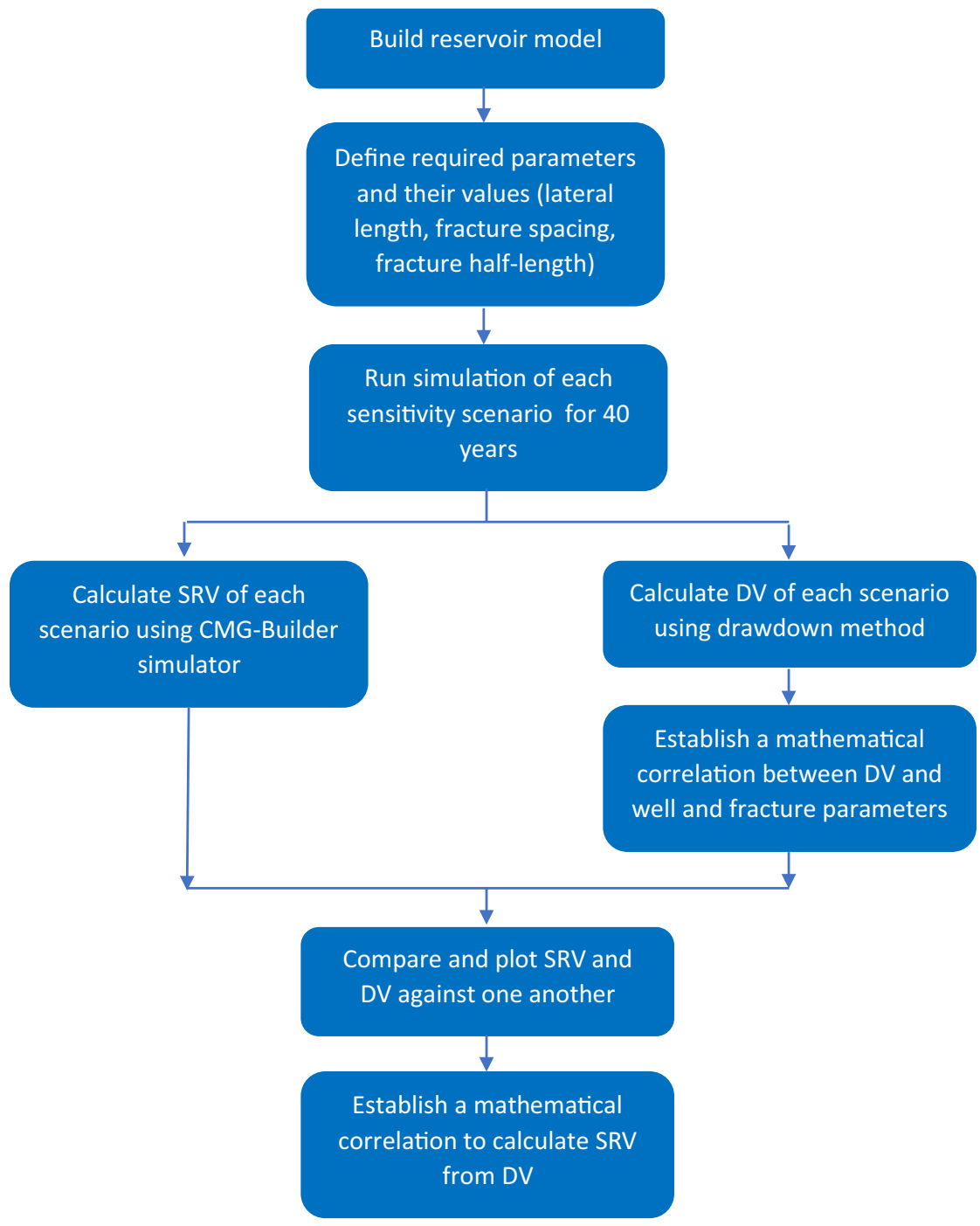

\section{References}

Bruner KR, Smosna R (2010) A Comparative Study of the Mississipian Barnett Shale, Fort Worth Basin, and Devonian Marcellus Shale. Appalachian Basin, US Department of Energy, Washington, D.C.

Carpenter C (2014) Probabilistic Evaluation of global technically recoverable tight gas resources. Soc Petrol Eng. https://doi. org/10.2118/1014-0161-JPT

Chevallier B, Bordenave MK (1986) Contribution of Geochemistry to the Exploration in the Bintuni Basin, Irian Jaya. In: Indonesia Petroleum Association, 15th Annual Convention Proceedings. pp 439-460

Chong KK, Grieser WV, Passman A, Tamayo HC, Modeland N, Burke BE (2010) A completions guide book to shale-play development: a review of successful approaches toward shale-play stimulation in the last two decades. Soc Petrol Eng. https://doi. org/10.2118/133874-MS
Cipolla CL, Warpinski NR, Mayerhofer MJ, Lolon E, Vincent M (2008) The relationship between fracture complexity, reservoir properties, and fracture treatment design. In: SPE annual technical conference and exhibition, pp. 21-24. Denver. Available at: https ://www.onepetro.org/conference-paper/SPE-115769-MS

Computer Modelling Group CMG (2015) Suite Software Guide

Decker J, Bergman SC, Teas PA, Ballie P, Orange DL (2011) Constraints on the tectonic evolution of the bird's head, West Papua, Indonesia. In: Proceedings Indonesian petroleum association thirty-third annual convention and exhibition

Demirmen F (2005) Reliability and uncertainty in reserves: how and why the industry fails, and a vision for Improvement. Soc Petrol Eng. https://doi.org/10.2118/94680-MS

Dong Z, Holditch SA, McVay DA et al. (2012) Global unconventional gas resource assesment. SPE Econ Mgmt 4(4):222-234

EIA 2015. Technically recoverable shale oil and shale gas resources: Indonesia. In: US Energy Information Administration 
Elliott DC (1995) Reserve estimates: uncertainty and its implications. Petrol Soc Can. https://doi.org/10.2118/95-04-06

Grieser WV, Shelley RF, Johnson BJ et al. (2008) Data analysis of Barnett shale completions. SPE J 13(3):366-374. SPE-100674-PA

Gülen G, Ikonnikova S, Browning J, Smye K, Tinker SW (2015) Production scenarios for the haynesville shale play. In: SPE economics and management, pp 138-139. Available at: https://www. onepetro.org/journal-paper/SPE-176022-PA. Accessed 22 Mar 2018

Hayden J, Pursel D (2005) The Barnett Shale: Visitor's Guide to the Hottest Gas Play in the US. Pickering Energy Partners, Inc; Houston, Texas

Hefner JM, Thompson RS (1996) A comparison of probabilistic and deterministic reserve estimates: a case study. SPE Reservoir Eng 11:43-47. https://doi.org/10.2118/26388-PA

Jarvie DM, Pollastro R, Hill M (2004) Geochemical characterization of thermogenic gas and oil in the Ft. Worth Basin, Texas. Paper presented at AAPG National Convention, Dallas, Texas

Jones SC (1987) Using the Inertial Coefficient, $\beta$, To Characterize Heterogeneity in Reservoir Rock. Presented at the SPE Annual Technical Conference and Exhibition, Dallas, Texas, 27-30 September. SPE-16949-MS. https://doi.org/10.2118/16949-MS

Kenedy RB (2010) Shale Gas Challenges/Technologies Over the Asset Life Cycle. Paper present at US-China Oil and Gas Industry forum. Fort Worth, Texas

Kuuskraa VA, Koperna G, Schmoker J et al. (1998) Barnett shale rising star in Fort Worth basin. Oil Gas J 96(21):71-76

Martin SO, Holditch SA, Ayers WB, McVay DA (2010) PRISE Validates Resource Triangle Concept. In: SPE Eastern Regional/ AAPG Eastern Section Joint Meeting. Pittsburgh

Maxwell S, 2013. Beyond the SRV: The EPV Provides a More Accurate Determination of Reservoir Drainage in Shale Reservoirs. Schlumberger E\&P, (November)

Mayerhofer MJ, Lolon E, Warpinski NR, Cipolla CL, Walser DW, Rightmire CM (2010) What is stimulated reservoir volume? SPE
Production and Operations, pp. 89-92. Available at: https://www. onepetro.org/journal-paper/SPE-119890-PA

Medlock KB, Jaffe AM, Hartley PR (2011) Shale gas and U.S. National Security. Rice University Houston, TX

McGlade C, Speirs J, Sorrell S (2013) Methods of Estimating shale gas resources-comparisons, evaluation and implications. Energy 59:116-125

Montgomery SL, Jarvie DM, Bowker KA et al. (2005) Mississipian Barnett Shales, Fort Worth Basin, North-Central Texas: Gas Shale pay Multindashtrillion Cubic Foot Potential. AAPG Bulletin 89(2):155-175

Ovreberg O, Damaleth E, Haldorsen HH (1992) Putting error bars on reservoir engineering forecasts. Soc Petrol Eng. https://doi. org/10.2118/20512-PA

Powell G (2010) Shale energy: developing the Barnett-Lateral length Increasing in Barnett Shale. World Oil 231

Preiksaitis M, Bowman S, Urbancic TI, Baig A (2014) Enhanced Fluid Flow: An Improved Method for Estimating Stimulated Reservoir Volume. SPE/CSUR Unconventional Resources Conference. Calgary. Available at: https://www.onepetro.org/conference-paper/ SPE-171616-MS

Shahkarami A, Wang G, Belyadi H (2017) Horizontal Well Spacing and Hydraulic Fracturing Design Optimization: A Case Study on Utica-Point Pleasant Shale Play. SPE Eastern Regional Meeting. Kentucky. Available at: https://www.onepetro.org/conference -paper/SPE-187511-MS

Wattenbarger RA, Ramey HJ (1968) Gas Well Testing With Turbulence, Damage and Wellbore Storage. J Pet Technol 20(8):877887. https://doi.org/10.2118/1835-PA

Publisher's Note Springer Nature remains neutral with regard to jurisdictional claims in published maps and institutional affiliations. 